\title{
A NOTE ON AIR TEMPERATURE LAPSE RATES ON MOUNT WELLINGTON, TASMANIA
}

\author{
by M. Nunez and E.A. Colhoun
}

(with three tables and one text-figure)

NUNEZ, M. \& COLHOUN, E.A., 1986 (12:ix): A note on air temperature lapse rates on Mount Wellington, Tasmania. Pap. Proc. R. Soc. Tasm. 120: 11-15. https://doi.org/10.26749/rstpp.120.11 ISSN 0080-4703. Department of Geography, University of Tasmania, Hobart, Australia, and Department of Geography, Newcastle University, Newcastle, Australia.

Temperature lapse rates are derived from field measurements taken on Mt Wellington over a one year period. The results are compared with regional lapse rates for the state. The agreement is best with maximum temperatures in winter and minimum temperatures in summer. The agreement is poor with other combinations. This is due to oceanic and continental effects.

Key Words: temperature lapse rates, Tasmania.

\section{INTRODUCTION}

The gradient of air temperature with altitude, commonly known as the environmental lapse rate (ELR), is a widely documented phenomenon (see Barry 1981). Many factors influence the ELR and mainly involve thermal characteristics of surface features such as topography, vegetation and soil type. In general these factors make the ELR very site-specific requiring, in most cases, direct experimental measurements, (Richardson \& Linacre 1977; Tapp 1978; Kernich \& Robin 1979; Manins \& Sawford 1979). Of more applicability to ecological and palaeoclimatic work is the change in near ground level air temperature with terrain altitude (Macphail 1979; Kirkpatrick 1982; Colhoun 1985). This form of ELR, to be distinguished from "free air" ELR, is sometimes used as an aid in palaeoenvironmental reconstructions. However, little attempt has been made to distinguish between and compare temperature lapse rates obtained from a single steep mountain slope with regional lapse rates that are generally obtained from measurements taken at individual stations often located in different topographic situations in highland areas. It is the purpose of this paper to investigate, using air temperature measurements taken at $\mathrm{Mt}$ Wellington, the relationship between lapse rates on a single north-facing mountain slope and those obtained from Tasmanian climatological stations.

\section{DATA}

Daily maximum and minimum temperatures, grass minimum temperatures and thermograph records were obtained at six stations that extend from sea level to the summit of $\mathrm{Mt}$ Wellington (table 1). The study period extended from April 1, 1978 to March 31, 1979.

All sites with the exception of the Chalet had a good sky view. The environment surrounding the Chalet site was lightly forested, but the equipment was placed in an opening with scrub which not only gave a good sky vi@w but was fairly representative of the general surroundings. Maximum/minimum thermometers (Dobbie Brothers) were located at a height of $1.5 \mathrm{~m}$ above the ground, facing south, and attached to a wooden post with a horizontal and vertical shield to provide protection against direct sunlight. Thermograph records were obtained with Casella Thermo-hygrographs (Model 931) which were resting on bare ground. A white-painted louvred screen box with no bottom rested on top of the thermo-hygrographs thus providing protection against rain and snow. Casella grass minimum thermometers were used to record minimum ground temperatures.

Intercomparison tests were carried out on all the maximum/minimum thermometers and thermohygrographs before starting the project. Results showed that all instruments agreed to within their specification of $1^{\circ} \mathrm{C}$. Similar tests were not performed on the grass minimum thermometers since their accuracy $\left(0.2^{\circ} \mathrm{C}\right)$ far exceeded our ability to find similar microenvironment with which to test for consistency.

Despite the radiation shields, some direct solar radiation still reached the maximum/minimum thermometers during the daytime. This process gave readings for the daytime maximum air temperature that were too high. Maximum air temperatures were also a vailable from the thermo- 
hygrograph record, although problems with the ink supply made the records more sporadic than the daily observations of the maximum/minimum thermometers. To solve the problem a monthly correction figure was obtained by comparing the mean maximum temperature from the thermohygrograph records with simultaneous thermometer observations. This technique gave 12 data points for the year at each of the six stations. These data formed the basis of six regression relations which were applied to correct the more complete monthly average temperature data obtained by the thermometers. In general the technique gave satisfactory results, as shown by the Sandy Bay station which exhibited an average monthly temperature departure of $-0.4^{\circ} \mathrm{C}$ when compared to the readings from the Bureau of Meteorology office in Hobart. Such departure can be expected between an inner city recording station and a suburban station.

\section{RESULTS}

Initially, regressions of monthly temperature (maximum and minimum) versus height were obtained for each month. However, the lapse rates, defined as the slope of the regression relation, were not found to be statistically significant on a monthly basis. As a result all monthly data were pooled to give single relationships for maximum, minimum and grass minimum temperatures. These had the form:

(a) Maximum Temperature

$$
\begin{aligned}
& \overline{\mathrm{T}}_{\max }=11.05+\Delta \overline{\mathrm{T}}_{\max }-0.00751 \mathrm{H} \\
& \mathrm{R}^{2}=97.8 \%
\end{aligned}
$$

$$
\text { Std error in } \overline{\mathrm{T}}_{\text {max }}=0.79^{\circ} \mathrm{C}
$$

(b) Minimum Temperature

$$
\begin{aligned}
& \overline{\mathrm{T}}_{\min }=4.10+\Delta \overline{\mathrm{T}}_{\min }-0.00503 \mathrm{H} \\
& \mathrm{R}^{2}=97.5 \%
\end{aligned}
$$

$$
\text { Std error in } \overline{\mathrm{T}}_{\text {min }}=0.55^{\circ} \mathrm{C}
$$

(c) Grass Minimum Temperature

$$
\begin{aligned}
& \overline{\mathrm{T}}_{\mathrm{G} \min }=0.436+\Delta \overline{\mathrm{T}}_{\mathrm{G} \min }-0.00463 \mathrm{H}(3) \\
& \mathrm{R}^{2}=87.5 \%
\end{aligned}
$$

Std error in $\overline{\mathrm{T}}_{\mathrm{G} \min }=1.17^{\circ} \mathrm{C}$ $\begin{aligned} \text { where } \mathrm{T}_{\max }, & \overline{\mathrm{T}}_{\min }, \overline{\mathrm{T}}_{\mathrm{G} \min }= \\ & \text { monthly averages of maximum, } \\ & \text { minimumand grass minimum tempera- }\end{aligned}$ ture respectively $\left({ }^{\circ} \mathrm{C}\right)$,

$\Delta \overline{\mathrm{T}}_{\max }, \Delta \overline{\mathrm{T}}_{\min }, \Delta \overline{\mathrm{T}}_{\mathrm{G} \max }=$

difference between the monthly average maximum (minimum, grass minimum) temperatures and their respective July value (see table 2$)\left({ }^{\circ} \mathrm{C}\right.$ ),

and

$$
\mathrm{H}=
$$

altitude ( $m$ above sea level).

It may be seen from equations 1 and 2 that the lapse rates for maximum and minimum temperatures are $0.75^{\circ} \mathrm{C} / 100 \mathrm{~m}$ and $0.5 / 100 \mathrm{~m}$ respectively. Averaging these two values gives an approximation for the lapse rate of the daily mean temperature of $0.63^{\circ} / 100 \mathrm{~m}$.

The regression pattern for grass minimum temperature reveals temperatures 3 to $5^{\circ} \mathrm{C}$ cooler than the minimum temperatures for $1.5 \mathrm{~m}$ height at the same height. This is consistent with other studies that show a distinctive colder layer close to the ground during night-time cooling (Nunez \& Sander 1981; Bacock et al. 1977; Bootsma 1976).

The regression only explains $87.5 \%$ of the variance which is significantly lower than the equivalent figure for the regression of the minimum temperatures $(97.5 \%)$. This feature, along with a higher standard error of prediction, points to the marked microscale variability in grass minimum temperatures. Features such as ground type, soil moisture and cold air drainage all accentuate ground temperature differences which in some instances mask the environmental lapse rate.

The suitability of equations 1 and 2 for representing regional lapse rates can be tested using temperature residuals. For each month it is possible to define a mean residual $\bar{Y}_{\max }$ :

$$
\overline{\mathrm{Y}}_{\text {max }}=\sum_{i=1}^{\mathrm{N}}\left(\mathrm{T}_{\mathrm{i}}-\mathrm{T}_{\text {meas }}\right) / \mathrm{N}
$$

where $T_{i} \quad=$ estimate of mean maximum (minimum) temperature from equations l(2) $\left.{ }^{\circ} \mathrm{C}\right)$,

$\mathrm{T}_{\text {meas }}=$ measured mean maximum (minimum) temperature at station $\mathrm{i}\left({ }^{\circ} \mathrm{C}\right)$,

$\mathrm{N}=$ number of stations in Tasmania used in the analysis $(\mathrm{N}=30)$.

Residuals were calculated for the period April 1978 to March 1979, which corresponds in time with the data obtained for the $\mathrm{Mt}$ Wellington regression. Table 3 shows monthly estimates of $g$ for maximum and minimum temperatures. The standard deviation 
TABLE 1

Site Characteristics

\begin{tabular}{|c|c|c|c|c|}
\hline Site Name & Terrain & Slope & Aspect & $\begin{array}{l}\text { Elevation } \\
\text { (a.s.l.) }\end{array}$ \\
\hline Sandy Bay & suburban lawn & flat & - & $10 \mathrm{~m}$ \\
\hline Strickland Avenue & suburban lawn & slope & $\mathrm{N}$ & $180 \mathrm{~m}$ \\
\hline Pillinger Drive & suburban lawn & slope & $\mathrm{N}$ & $440 \mathrm{~m}$ \\
\hline The Springs & grass \& bare soil & flat & - & $700 \mathrm{~m}$ \\
\hline The Chalet & $\begin{array}{l}\text { subalpine forest } \\
\& \text { scrub }\end{array}$ & slope & $\mathrm{NE}$ & $990 \mathrm{~m}$ \\
\hline Summit & $\begin{array}{l}\text { dolerite rock \& } \\
\text { bare soil }\end{array}$ & flat & - & $1260 \mathrm{~m}$ \\
\hline
\end{tabular}

TABLE 2

Differences Between Monthly Average Maximum (Minimum) Temperatures and Their Respective July Value.

For any month $i$ the value of $\Delta \bar{T}_{i}$ is given as $\Delta \bar{T}_{i}=\bar{T}_{i}-T_{7}, \bar{T}_{i}$ is the average temperature for the six stations in month $i, T_{7}$ is the corresponding value for July.

\begin{tabular}{lrrrrrrrrrrrr} 
& $\mathbf{J}$ & $\mathbf{F}$ & $\mathbf{M}$ & $\mathbf{A}$ & $\mathbf{M}$ & $\mathbf{J}$ & $\mathbf{J}$ & $\mathbf{A}$ & $\mathbf{S}$ & $\mathbf{0}$ & $\mathbf{N}$ & $\mathbf{D}$ \\
$\overline{\mathbf{T}}_{\max }\left({ }^{\circ} \mathrm{C}\right)$ & 13.1 & 11.5 & 9.1 & 5.7 & 3.5 & 0.9 & 0.0 & 1.1 & 4.6 & 7.0 & 7.9 & 8.4 \\
$\overline{\mathbf{T}}_{\min }\left({ }^{\circ} \mathrm{C}\right)$ & 7.8 & 7.9 & 6.4 & 4.7 & 4.3 & 1.7 & 0.0 & 0.3 & 2.4 & 3.7 & 4.9 & 5.7 \\
\hline
\end{tabular}

\section{TABLE 3}

Mean Monthly Residuals ( $\bar{Y})$ Formed as the Differences Between the Mt Wellington Lapse Rates (Equations 1 and 2) and Measured Temperatures for 30 Stations in Tasmania, and Standard Deviations $(\sigma)$ of the Difference.

\begin{tabular}{rrrrrrrrrrrrrrr}
\hline & Apr & \multicolumn{1}{c}{ May } & Jun & Jul & Aug & Sep & Oct & Nov & Dec & Jan & Feb & \multicolumn{2}{c}{ Mar } \\
& -1.04 & -1.26 & -0.48 & -0.47 & -0.14 & 0.06 & 0.48 & -0.36 & -0.59 & -0.26 & -0.97 & -0.92 & $\bar{Y}$ \\
$\mathrm{~T}_{\max }$ & 1.06 & 0.61 & 1.04 & 0.76 & 0.75 & 0.67 & 1.17 & 1.17 & 1.18 & 1.61 & 1.69 & 0.90 & $\sigma$ \\
& 1.17 & 0.99 & 2.10 & 1.19 & 0.60 & 0.90 & 0.72 & 0.38 & -0.07 & 0.67 & 0.06 & -0.33 & $\mathrm{Y}$ \\
$\mathrm{T}_{\min }$ & 1.20 & 1.26 & 1.56 & 1.48 & 1.07 & 1.24 & 0.88 & 0.80 & 0.73 & 1.58 & 1.08 & 1.38 & $\sigma$ \\
\hline
\end{tabular}

$(\sigma)$ of the difference is also shown. On a monthly basis, the temperature measurement error of $1^{\circ} \mathrm{C}$ reduces to just over $0.2^{\circ} \mathrm{C}$, which is a figure lower than most of the residuals shown in the table. This treatment naturally assumes a rand om error in the temperature measurement.

The results shown in table 3 reflect the effect of continentality in Tasmania. Residuals in maximum temperature are mostly negative as most inland stations would be warmer than the equivalent temperatures on Mt Wellington. As expected the residual values become more pronounced in late summer and autumn, and are slightly positive in winter. The standard deviations are also largest in summer since thermal circulation processes such as sea breezes and anabatic winds would be acting then, thus bringing a degree of spatial inhomogeneity to the area. 
(a)

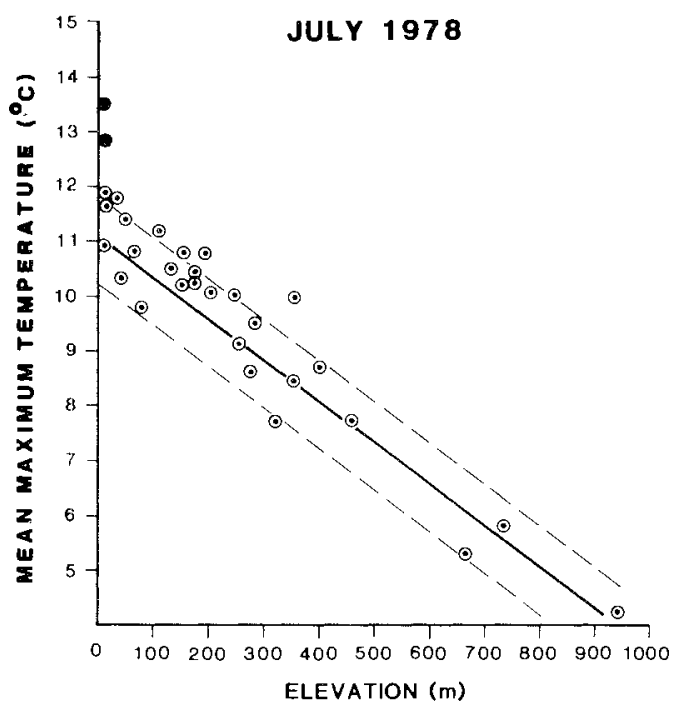

(c)

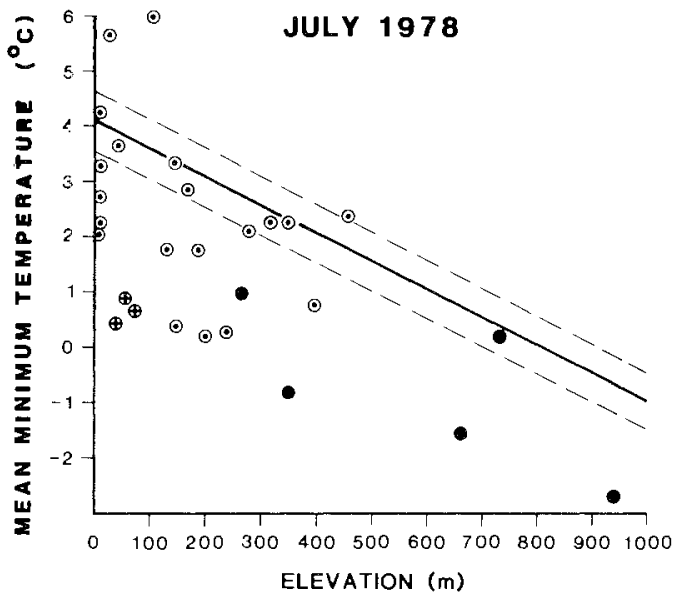

FIG.1 - Plot of mean maximum (minimum) air temperature versus elevation for 30 stations in Tasmania. The Mt Wellington temperatures are

The residuals in minimum temperature become most positive in winter, again reflecting the effect of continentality. Standard deviations are quite varied with a notable peak in mid-winter (June, July) and in January, and lower values in spring and early summer (October-December). Localized cooling effects such as cold air drainage and cold air ponding are most pronounced in winter, although these effects act to a lesser degree throughout the year.

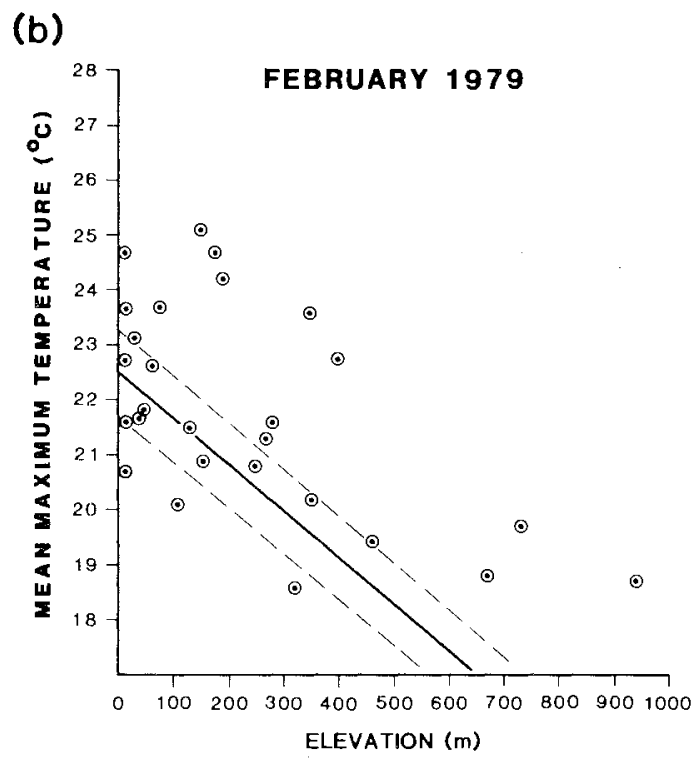

(d)

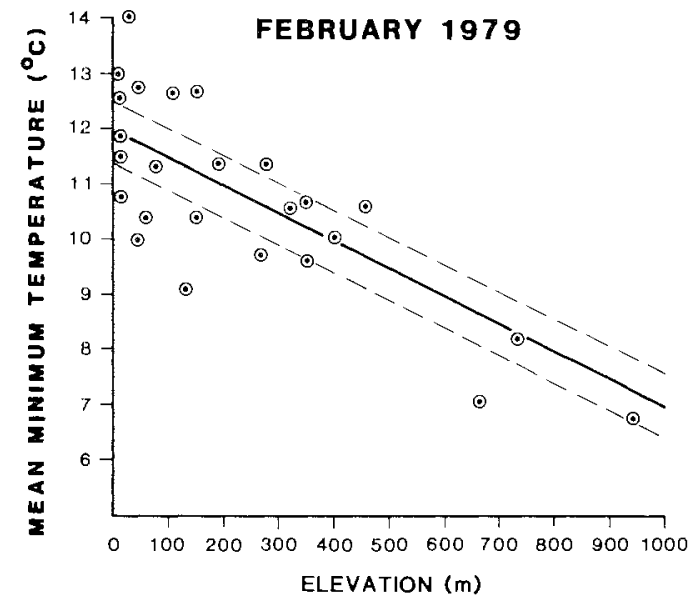

represented by the solid lines. The dashed lines represent the range of their standard error.

Figure 1 shows the regional lapse rates for the two extreme months, February and July. Also shown is the regression line from the $\mathrm{Mt} \mathrm{Wellington}$ data, with the dashed lines denoting the range of the standard error. Approximately $66 \%$ of the maximum temperatures in July fall within the standard error bars. The two extreme deviations shown as black circles in figure la, represent the east coast stations of Orford $\left(12.9^{\circ} \mathrm{C}\right)$ and St Helens $\left(13.5^{\circ} \mathrm{C}\right)$. Very little pattern appears in the 
February maxima. The regression relation substantially underpredicts the minima on the north and east coasts, and in the midlands area of Tasmania. Approximately $83 \%$ of the July minima are below the regression line, with extreme departures being reported on the Central Plateau and western highlands (black circles) and southeast (crosses). These low values in the southeast are probably due to the result of katabatic channelling of cold winds. Substantial improvement occurs in the February minimum temperatures, as $36 \%$ of the data points fall within the standard error bars. This indicates that "anomalies" of minima due to high altitude effects or cold air drainage are much less likely to occur in summer than in winter.

\section{DISCUSSION AND CONCLUSION}

It is evident from the above results that temperature lapse rates are site specific. On a microscale such factors as slope, aspect, sky view factor, ground characteristics, etc. will affect both the maximum and minimum temperatures. As a result there will be some variability in lapse rates at specific mountain sites such as Mt Wellington (equations 1-3).

At a regional scale other processes (sea breezes, katabatic and anabatic winds, etc.) dominate the variability in temperatures and regional lapse rates. The results presented here show that the Mt Wellington lapse rates do not agree with regional lapse rates for a substantial part of the year. Agreement is best during the time of year when the continental effect is minimized. This condition would occur with maximum temperatures in winter and minimum temperatures in summer. Unfortunately the temperature extremes are the important variables in climate analysis. Similarly, ecological studies use maximum temperatures in summer as a surrogate for climate control on plant growth (Kirkpatrick, pers. comm.). In addition, geomorphic processes are enhanced strongly as thresholds are crossed; for example, freeze-thaw action, which is much more likely with extreme than with average values.

Based on this study it would seem that lapse rates should be studied for specific sites or mountain ranges. It remains to be ascertained if different mountain ranges have the same lapse rates even if their base temperatures differ. Clearly it is not possible to assign a single lapse rate applicable throughout Tasmania since regional effects dominate and should cause differences. Botanical studies that investigate ecological zonation with altitude and palynological studies that infer vegetation history and palaeoclimate should recognize the regional nature of the climatic environment of their study area. A proper assessment of temperature change with height should involve firstly a delineation of the climatic region boundaries. Only a lapse rate derived from data collected within these boundaries would be relevant.

\section{ACKNOWLEDGEMENTS}

The authors thank Mr D. Charlesworth, and staff members of the Australian Broadcasting Corporation, the Tasmanian National Parks and Wild life Service, and the Hobart City Council who helped with the data collection. They also thank Mrs Kate Charlesworth for drafting the figures, and Miss Ifay Tsang for typing the manuscript.

\section{REFERENCES}

BARRY, R.G., 1981: MOUNTAIN WEATHER AND CLIMATE. Methuen: $313 \mathrm{pp}$

BACOCK, K.L., JEFFERS, J.N.R., LINDLEY, D.K., ADAMSON, J.K. \& GILL, C.A., 1977: Estimating woodland soil temperature from air temperature and other climatic variables. Agricultural Meteorology 18: 351-372.

BOOTSMA, A., 1976: Estimating grass minimum temperatures from screen minimum values and other dimatological parameters. Agricultural Meteorology 16: 103-113.

COLHOUN, E.A., 1985: Glaciations of the west coast range, Tasmania. Quaternary Research 24: 39-59.

KERNICH, A.M. \& ROBIN, A.G., 1979: Tethered balloon soundings of temperature and wind at Monarto, South Australia. Meteorological Note 106, Bureau of Meteorology, Melbourne: $14 \mathrm{pp}$.

KIR KPATRICK, J.B., 1982: Phytogeographical analysis of Tasmanian alpine floras. Journal of Biogeography 9: 255-271.

MACPHAIL, M.K., 1979: Vegetation and climates in southern Tasmania since the last glaciation. Quaternary Research I1: 306-341.

MANINS, P.C. \& SAWFORD, B.L., 1979: Katabatic winds: a field case study. Quart. J. R. Meteor. Soc. 105: 1011-1025.

NUNEZ, M. \& SANDER, D., 198I: Frost protection in a high altitude shelterwood. Univ. Tasm. Dept Geog. Occ. Pap. 9: 35 pp.

RICHARDSON, B.J. \& LINACRE, E.T., 1977 : Atmospheric stability in the Hawkesbury River Valley in winter. Aust. Geogr. Studies 15: 42-52.

TAPP, R.G., 1978: A mesomete orological study using a tethered balloon sounding system in a region of proposed urban development: Albury-Wodonga. Aust. Meteor. Mag. 26: 107-124.

(accepted May 23, 1986) 